\title{
LETTER TO THE EDITOR \\ The reliability of measuring wound undermining in people with spinal cord injury
}

Spinal Cord (2017) 55, 794; doi:10.1038/sc.2017.62; published online 30 May 2017

I was glad to read in the contribution of Arora et al. ${ }^{1}$ that they found that the inter-rater and intra-rater reliability of measuring wound undermining in people with spinal cord injury was 0.996 and 0.998 with a percent close agreement $>90 \%$ when the undermining measures $>0.5 \mathrm{~cm}$. These findings support the results of similar research we published in 1997 and 1998.,3 Our conclusions escaped international attention, probably because they were only published in Dutch. Based on this research, we designed a local wound measurement protocol in which length, width, depth and the greatest undermining were rounded up to $0.5 \mathrm{~cm}$ and registered in a graph weekly. Since that time this protocol (working name 'Decu-stick' protocol) has been in use for in-patients and out-patients in the spinal unit in Utrecht and several other units in the Netherlands. Data collected in this way gave us the opportunity to design an algorithm for the prediction of wound healing. Details of this way of wound measurement and wound-healing prediction were published in this journal in 2015. ${ }^{4}$ The use of plain sterile swabs instead of specially designed Decu-sticks is now being tested. An application for digital registration is under construction following the Standards of the International Spinal Cord Injury Skin and Thermoregulation Function Basic Data Set. ${ }^{5}$ Interested clinicians and researchers are advised to visit the instruction website www.decu-stick.org (English version available) for further information.

\section{CONFLICT OF INTEREST}

The author declares no conflict of interest.

FWA van Asbeck ${ }^{1,2}$

${ }^{1}$ SCI Unit, De Hoogstraat Rehabilitation, Utrecht, The Netherlands and ${ }^{2}$ Center of Excellence in Rehabilitation Medicine, Brain Center Rudolf Magnus, University Medical Center Utrecht, Utrecht, The Netherlands E-mail: fvasbeck@tiscali.nl

1 Arora M, Harvey LA, Chhabra HS, Sharawat R, Glinsky JV, Cameron ID. The reliability of measuring wound undermining in people with spinal cord injury. Spinal Cord 2017; 55: 304-306.

2 Van Asbeck FW. De DECU-stick: een eenvoudige manier om decubitus te meten. Ned Tijdschr Geneesk 1997; 141: 1718.

3 Van Asbeck FW. De 'Decu-stick'; een werkelijk eenvoudige manier om decubitus te meten. Revalidata 1998; 20: 17-18.

4 Van Asbeck FW, Post MWM. Bedside prediction of the progress of pressure ulcer healing in patients with spinal cord injury using the 'Decu-stick'. Spinal Cord 2015; 53: 539-543.

5 Biering-Sørensen F, Alexander MS, van Asbeck FWA, Donovan W, Krassioukov A, Post MWM. Version 1.1 of the international spinal cord injury skin and thermoregulation function basic data set. Spinal Cord 2017; 55: 566-569. 